\title{
PROFIL OTOMATISASI DISTRIBUSI SISTEM TENAGA LISTRIK UNIVERSITAS BHAYANGKARA SURABAYA
}

\author{
Agus Kiswantono $^{(1)}$, E Nur Cahyono $^{(1)}$, Hermawan $^{(1)}$ \\ Program Studi Elektro, Universitas Bhayangkara Surabaya \\ kiswantono@gmail.com
}

\begin{abstract}
Abstrak.
Transmisi Tenaga Listrik yaitu Merupakan proses penyaluaran tenaga listrik dari tempat pembangkit tenaga listrik (Power Plant) hingga Saluran distribusi listrik (substation distribution) sehingga dapat disalurkan sampai pada konsumen pengguna listrik. . Human Machine Interface (HMI) adalah sistem yang menghubungkan antara manusia dan mesin. HMI dapat berupa pengendali dan visualisasi status, baik dengan manual maupun melalui visualisasi komputer yang bersifat real time. .Microsoft Visual Basic .NET adalah sebuah alat untuk mengembangkan dan membangun aplikasi yang bergerak di atas sistem .NET Framework. Arduino adalah sebuah mikrokontroller yang sudah dikembangkan. Komunikasi serial adalah salah satu metode komunikasi data di mana hanya satu bit data yang dikirimkan melalui seuntai kabel pada suatu waktu tertentu.
\end{abstract}

Kata kunci: Transmisi tenaga listrik, HMI ,Visual Basic .Net, Arduino, Komunikasi Serial

\begin{abstract}
.
Electric Power Transmission is the process of transmitting electricity from the power plant (Power Plant) to the electricity distribution channel (substation distribution) so that it can be distributed to electricity users. . Human Machine Interface (HMI) is a system that connects humans and machines. HMI can be in the form of controlling and visualizing status, either by manual or through computer visualization that is real time. Microsoft Visual Basic.NET is a tool to develop and build applications that move on the .NET Framework system. Arduino is a microcontroller that has been developed. Serial communication is one method of data communication where only one bit of data is sent through a cable at a certain time.
\end{abstract}

Keywords: Electric power transmission, HMI, Visual Basic.Net, Arduino, Serial Communication

\section{PENDAHULUAN}

Di dalam dunia industri yang berkembang ini transmisi tenaga merupakankomponen terpenting. Transmisi tenaga ini digunakan untuk penyaluran tenaga listrik sampai ke panel distribusi lalu disalurkan pada konsumen dan HMI ( Human Machine Interface ) sangatlah dibutuhkan untuk proses pengendalian dan memantau sebuah system atau alat. Alat pendukung pun beragam seperti mikrokontroller Arduino maupun PLC ( Programable Logic Controller ) dengan komunikasi serial dapat dilakukan pengendalian dengan mudah dan proses pengiriman data dengan cepat.

Banyak cara untuk membuat software, salah satunya menggunakan Visual Basic
Net. Dengan software berbasis Net Framework ini memudahkan pengguna untuk membuild sebuah software dengan GUI yang sangat bagus dan kehandalan software. Ada berbagai cara untuk mengkoneksikan sebuah software dengan hardware salah satunya yaitu menggunakan komunikasi serial. Komunikasi serial ini sangatlah populer dan kebanyakan didunia industri.

\section{Transmisi Tenaga Listrik}

Transmisi tenaga listrik merupakan proses penyaluaran tenaga listrik dari tempat pembangkit tenaga listrik (Power Plant) hingga Saluran distribusi listrik (substation distribution) sehingga dapat disalurkan sampai pada konsumen pengguna listrik. Dalam kontaks pembahasan ini, yang dimaksud transmisi (penyaluran) adalah 
Penyaluran energi listrik sehingga mempunyai listrik, maksud proses dan cara menyalurkan energi listrik dari satu tempat ke tempat lainnya (Setiono \& Prasetyo, 2016), misalnya : 1) Dari pembangkit listrik ke gardu induk. 2) Dari satu gardu induk ke gardu induk lainnya. 3) Dari gardu induk ke jaring tegangan menengah dan 4) gardu distribusi (App, 2019) . Ketentuan Dasar Sistem Tenaga Listrik. 1) Menyediakan setiap waktu, tenaga listrik untuk keperluan konsumer (Iqtimal \& Devi, 2018). 2) Menjaga kestabilan nilai tegangan, dimana tidak lebih toleransi $\pm 10 \%$ (Farida, n.d.). 3) Menjaga kestabilan frekuensi, dimana tidak lebih toleransi \pm 0 1Hz. 4) Harga yang tidak mahal (Efisien). 5) Standar keamanan (safety). 6) Respek terhadap lingkungan.

\section{Visual Basic Net}

Microsoft Visual Basic .NET adalah sebuah alat untuk mengembangkan dan membangun aplikasi yang bergerak di atas sistem .NET Framework, dengan menggunakan bahasa BASIC. Dengan menggunakan alat ini, para programmer dapat membangun aplikasi Windows Forms, Aplikasi web berbasis ASP.NET, dan juga aplikasi command-line. Alat ini dapat diperoleh secara terpisah dari beberapa produk lainnya (seperti Microsoft Visual $\mathrm{C}++$, Visual $\mathrm{C \#}$, atau Visual J\#), atau juga dapat diperoleh secara terpadu dalam Microsoft Visual Studio . NET. Bahasa Visual Basic . NET sendiri menganut paradigma bahasa pemrograman berorientasi objek yang dapat dilihat sebagai evolusi dari Microsoft Visual Basic versi sebelumnya yang diimplementasikan di atas .NET Framework. Peluncurannya mengundang kontroversi, mengingat banyak sekali perubahan yang dilakukan oleh Microsoft, dan versi baru ini tidak kompatibel dengan versi terdahulu.

\section{Advance Installer}

Advanced installer adalah software terbaru untuk membuat file installer dengan mudah. Software yang satu ini sangat cocok bagi sobat yang suka membuat program atau software, namun program tersebut hanya dapat dijalankan secara portable. Selain dapat membuat Installer, software Advanced Installer ini juga dapat digunakan untuk membuat Java, Update Patch, Add In, Merge Modules, dan lain-lain.

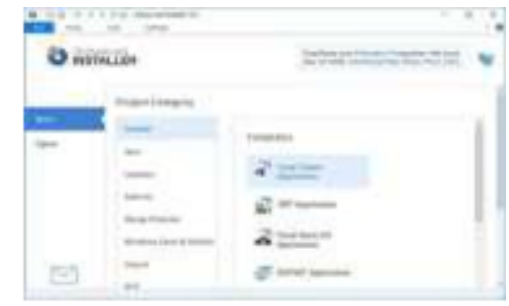

Gambar 1. Software Advance

Microsoft Access (atau Microsoft Office Access) adalah sebuah program aplikasi basis data komputer relasional yang ditujukan untuk kalangan rumahan dan perusahaan kecil hingga menengah. Aplikasi ini merupakan anggota dari beberapa aplikasi Microsoft Office, selain tentunya Microsoft Word, Microsoft Excel, dan Microsoft PowerPoint. Aplikasi ini menggunakan mesin basis data Microsoft Jet Database Engine, dan juga menggunakan tampilan grafis yang intuitif sehingga memudahkan pengguna.

Microsoft Access dapat menggunakan data yang disimpan di dalam format Microsoft Access, Microsoft Jet Database Engine, Microsoft SQL Server, Oracle Database, atau semua kontainer basis data yang mendukung standar ODBC. Para pengguna/programmer yang mahir dapat menggunakannya untuk mengembangka perangkat lunak aplikasi yang kompleks, sementara para programmer yang kurang mahir dapat menggunakannya untuk mengembangkan perangkat lunak aplikasi yang sederhana. Access juga mendukung teknik-teknik pemrograman berorientasi objek, tetapi tidak dapat digolongkan ke 
dalam perangkat bantu pemrograman berorientasi objek.

\section{Arduino Uno}

Advanced installer adalah software terbaru untuk membuat file installer dengan Arduino adalah pengendali mikro singleboard yang bersifat open-source, diturunkan dari Wiring platform, dirancang untuk memudahkan penggunaan elektronik dalam berbagai bidang. Hardwarenya memiliki prosesor Atmel AVR dan software nya memiliki bahasa pemrograman sendiri. Arduino Uno adalah board mikrokontroler berbasis ATmega328. Uno memiliki 14 pin digital input / output (dimana 6 dapat digunakan sebagai output PWM), 6 input analog, resonator keramik $16 \mathrm{MHz}$, koneksi USB, jack listrik, header ICSP, dan tombol reset. Uno dibangun berdasarkan apa yang diperlukan untuk mendukung mikrokontroler, sumber daya bisa menggunakan power USB (jika terhubung ke komputer dengan kabel USB) dan juga dengan adaptor atau baterai. Arduino Uno berbeda dari semua papan sebelumnya dalam hal tidak menggunakan. FTDI chip driver USB-to-serial. Sebaliknya, fitur Atmega16U2 (Atmega8U2 sampai versi R2) diprogram sebagai konverter USB-to-serial. Revisi 2 dari Uno memiliki resistor pulling 8U2 HWB yang terhubung ke Ground, sehingga lebih mudah untuk menggunakan mode DFU.

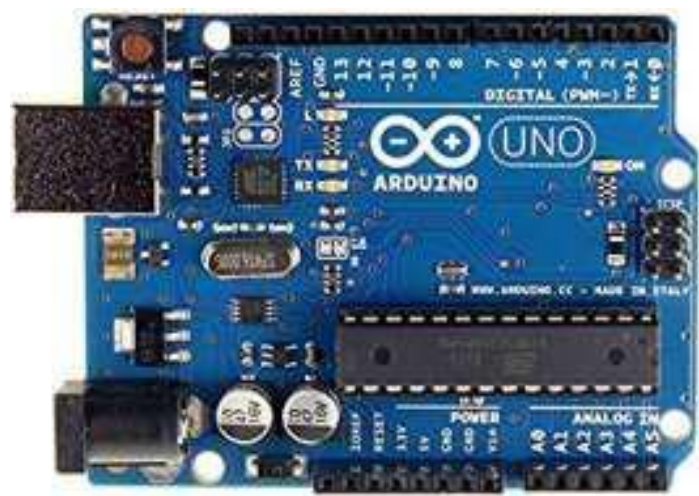

Gambar 2. Mikrokontroller Arduino Uno

Tabel 1. Spesifikasi Arduino Uno

\begin{tabular}{l|l}
\hline Mikrokontroler & ATmega328 \\
\hline Operasi tegangan & 5 Volt \\
\hline Input tegangan & disarankan 7-11Volt \\
\hline $\begin{array}{l}\text { Input tegangan } \\
\text { Batas }\end{array}$ & 6 -20Volt \\
\hline Pin I/O digital & $14(6$ bisa untuk \\
\cline { 2 - 2 } & PWM $)$ \\
\hline Pin Analog & 6 \\
\hline Arus DC tiap pin & $50 \mathrm{~mA}$ \\
I/O & \\
\hline Arus DC ketika & $50 \mathrm{~mA}$ \\
$3.3 \mathrm{~V}$ & \\
\hline Memori flash & $32 \mathrm{~KB}(\mathrm{ATmega328})$ dan \\
& $0,5 \mathrm{~KB}$ digunakan oleh \\
\hline SRAM & bootloader \\
\hline EEPROM & $2 \mathrm{~KB}(\mathrm{ATmega328})$ \\
\hline Kecepatan clock & $1 \mathrm{~KB}(\mathrm{ATmega328})$ \\
\hline
\end{tabular}

\section{Kabel USB 2.0 type A/B}

Kabel ini digunakan sebagai memasok tegangan, mamasukan program kedalam Arduino, dan sebagai komunikasi serial. Contoh gambar USB 2.0 type A/B dapat dilihat pada gambar 3 .

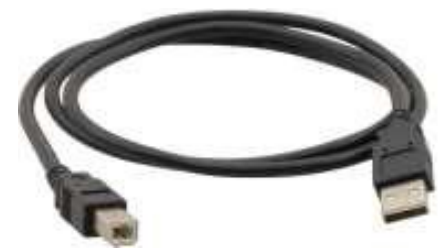

Gambar 3. USB2.0 type A/B 


\section{Led}

Kabel ini digunakan sebagai memasok tegangan, mamasukan program kedalam Arduino, dan sebagai komunikasi serial. Contoh gambar USB 2.0 type A/B. Diode pancaran cahaya / LED ( Light emitting diode ) adalah suatu semikonduktor yang memancarkan cahaya monokromatik yang tidak koheren ketika diberi tegangan maju. Led ini digunakan sebagai media output pada software maket ini.

\section{METODE PENELITIAN}

Di dalam pembuatan pemaket ini transmisi yang digunakan yaitu menggunakan jalur tanah $\mathrm{Di}$ dalam pembuatan software ini menggunakan Visual Basic Net. Untuk keamanan software ini menggunakan system login yang dibedakan 2 akses yaitu akses sebagai admin dan akses sebagai user yang menggunakan Microsoft Office Acces dengan fiturnya yakni Microsoft Jet Engine yang diakses oleh Software yang dibuat oleh Visual Basic Net ini. Pada tahap awal yaitu mendesain Form Login dan Form untuk pengontrol dan monitoring yang ada pada Visual Basic Net dengan Skin agar GUI Form terlihat lebih bagus.

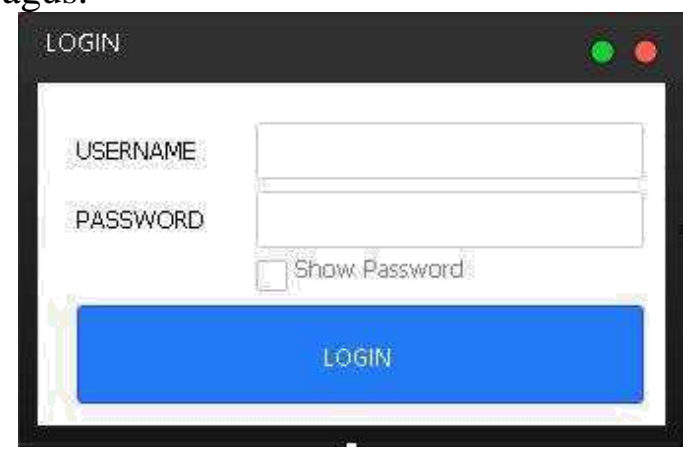

Gambar 4. Form Login

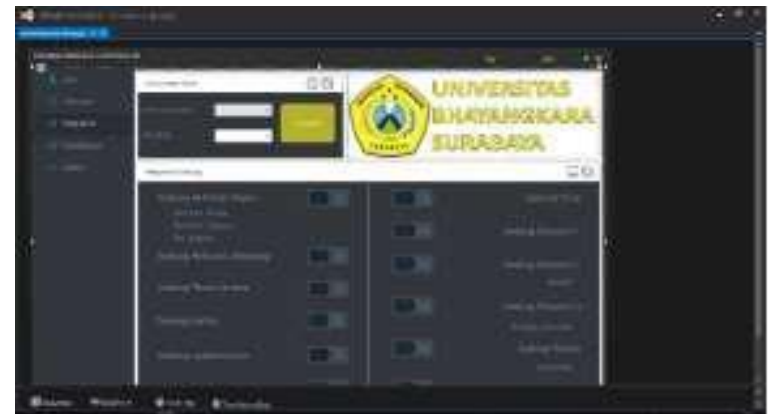

Gambar 5. Form Pengontrol dan monitoring

Setelah itu pembuatan database menggunakan Microsoft office access sebagai keamanan dari software yang akan dibuat. Didalam pembuatan database ini dilengkapi dengan password untuk membuka file Microsoft office access. Setelah pembuatan database selesai, maka dilanjutkan dengan penulisan koding pada Visual Basic Net. Pada pembuatan software ini menggunakan parsing data sebagai monitoring dan untuk controlling mengirimkan data berbentuk string. Agar mudah untuk berkomunikasi dengan mikrokontroller Arduino.

Penulisan koding pemrograman Arduino dengan logika membaca pin output untuk monitoring pin yang sedang aktif dan pin yang sedang tidak aktif dengan led sebagai output dan logika ketika software menerima data dalam bentuk string. Lalu dikirim data logika dan diterima data dalam bentuk string tersebut pada software yang telah dibuat dengan melakukan debugging pada Visual Basic Net untuk uji coba software.

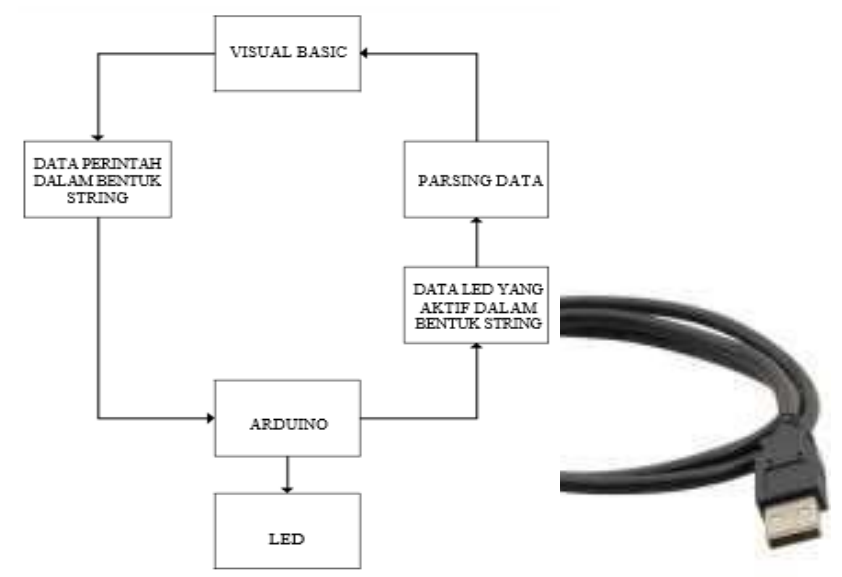


Gambar 6. Diagram Blok Logika

Pembuatan installer sangatlah diperlukan dalam membuat software, agar software dapat di jalankan oleh PC atau Laptop. Pembuatan installer ini menggunakan software Advance Installer lalu akan berbentuk installer dengan file ".exe". led sebagai penerangan Gedung tersebut. Untuk Transmisi yang digunakan menggunakan pengkabelan ducting bawah tanah. Didalam pemaketan ini pengkabelan dilakukan dibawah multiplek agar lebih efisien.

\section{HASIL DAN PEMBAHASAN}

Hasil dari pembuatan software diperlukan melakukan menginstall software yang telah dibentuk oleh Software Advance Installer. Pengontrolan Maket Gedung UBHARA berdasarkan MDP (Main Distribusi Panel).

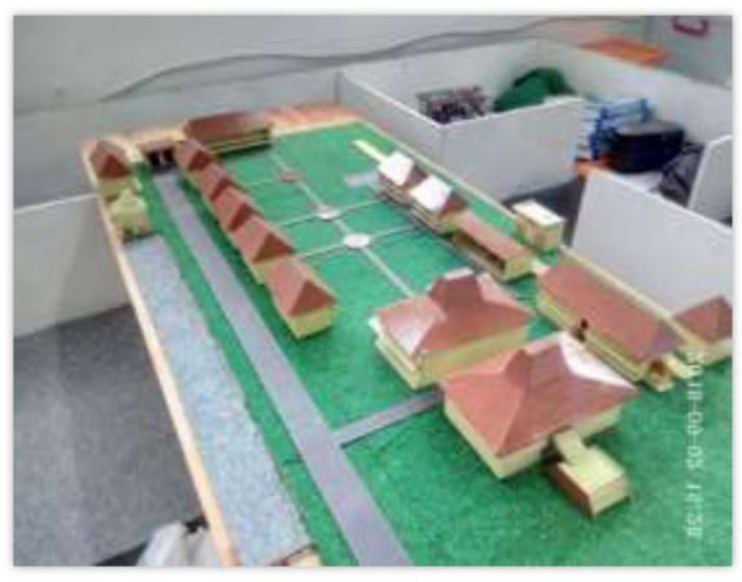

Gambar 7. Gedung Maket UBHARA

Apabila salah satu toggle pada software

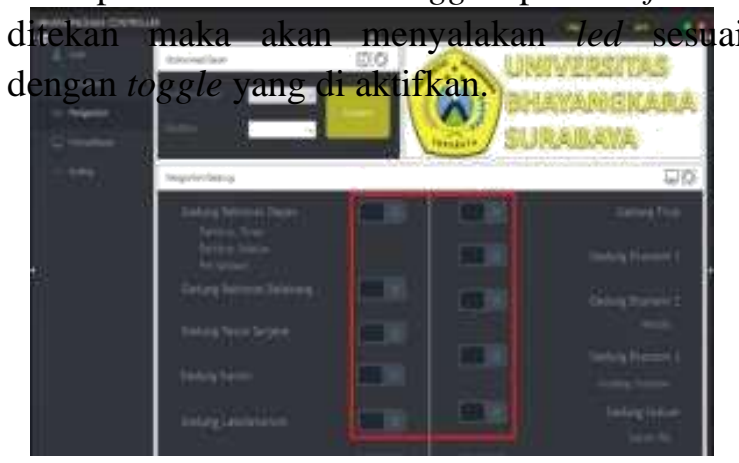

Gambar 8. Toggle Pengontrol

Ketika aktif dibagian tab pengontrolan toggle akan berwarna kuning ketika aktif dan dibagian tab pemantauan didalam software akan menyalakan text yang sebelumnya berwarna abu-abu menjadi warna hijau ketika aktif. Untuk mempermudah user dalam melakukan montoring dan controlling.

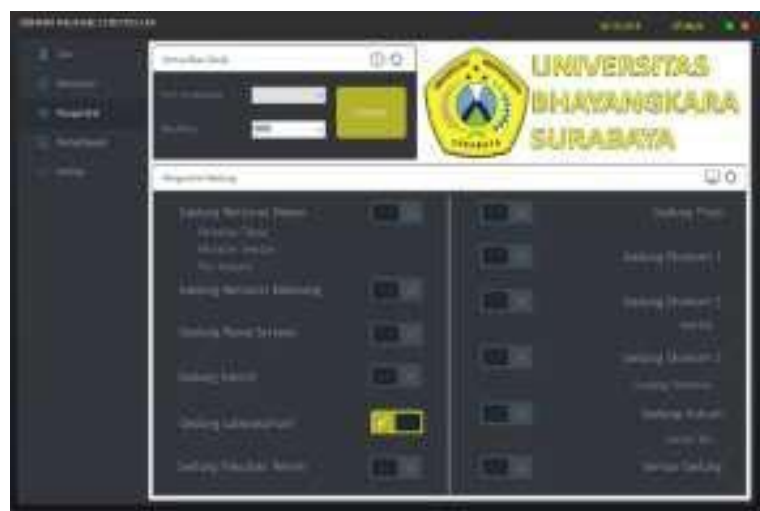

Gambar 9. Tab pengontrolan ketika Toggle ketika aktif

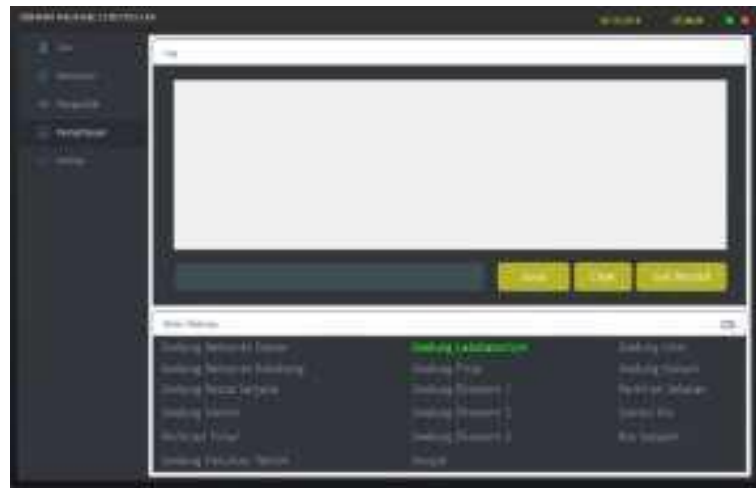

Gambar 10. Tab pemantauan ketika led pada Mikrokontroller Arduino aktif

Penambahan user, pengeditan user dan penghapusan user dapat dilakukan didalam software yang telah terintegrasi dengan Microsoft Office Acces . Sehingga user tidak perlu membuka file database pada Microsoft Office Access. 


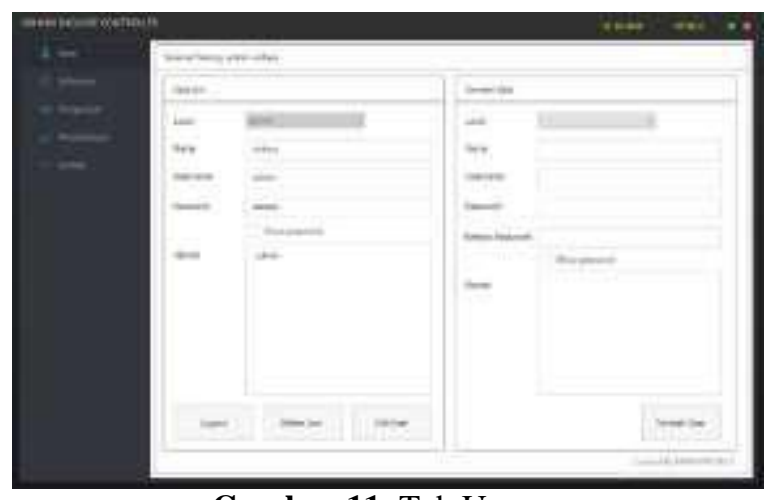

Gambar 11. Tab User

Dibagian tab informasi berisi tentang cara penggunaan software fungsi setiap Tab, dan untuk dibagian tab Koding adalah listing koding untuk Arduino untuk antisipasi apabila Arduino mengalami kerusakan dan membutuhkan Arduino yang baru. User dapat menggunakan koding tersebut.

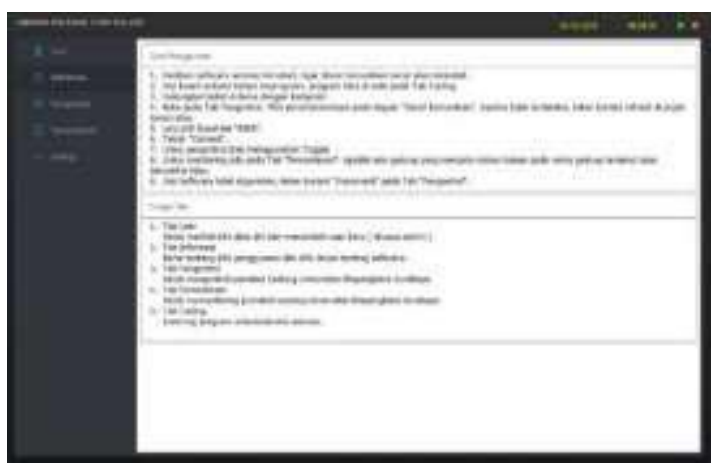

Gambar 12. Tab Informasi

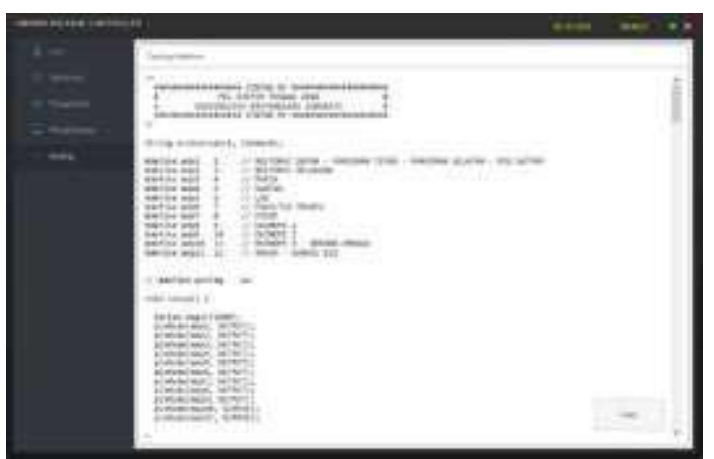

Gambar 13. Tab Koding

\section{KESIMPULAN}

Pada pembuatan software diperlukan parsing data dari Arduino ke Software yang dibuat dan pengiriman data dari Software ke Arduino melalui kabel untuk komunikasi serial. Parsing data difungsikan sebagai untuk mengetahui led mana yang aktif dan yang tidak aktif. Pengontrolan dan monitoring diperlukan keamanan pada software agar tidak semua orang dapat melakukan pengontrolan dan

monitoring. Sehingga hanya orang atau user tertentu yang dapat menggunakan software ini.

\section{Saran}

Saran untuk pembuatan software HMI selanjutnya adalah dapat dikontrol tanpa menggunakan kabel usb sebagai komunikasi serial atau dapat menggunakan wireless sebagai pengganti komunikasi.

\section{DAFTAR PUSTAKA}

App, M. I. T. (2019). Monitoring penyimpanan dan penyaluran energi listrik. 6(2), 2766-2775.

Farida, Y. (n.d.). Metode Logika Fuzzy Sebagai Related papers.

Noviardi. 2016. Aplikasi Komunikasi Serial Arduino Uno R3 pada pengontrolan dengan menggunakan visual studio 2012 dan Sql Server 2008

Iqtimal, Z., \& Devi, I. (2018). Aplikasi Sistem Tenaga Surya Sebagai Sumber Tenaga Listrik Pompa Air. Kitektro, 3(1), 1-8.

Setiono, I., \& Prasetyo, D. (2016). Rendah Dengan Menggunakan Fuse Cut Out. Fakultas Teknik Universitas Diponegoro, 298305. 
Supatmi, Sri. 2010. Simulasi

Pengontrolan Lampu Gedung

Menggunakan Visual Basic.

UNIKOM. Bandung. 